\title{
Matt Gorzalski
}

\section{Archives and non-Humanities students}

\section{Teaching with primary sources beyond document analysis}

O ver the last 30 years, archivists have increasingly integrated primary sources into $\mathrm{K}-12$ and higher education classrooms. This is rooted in evolving trends in the educational and archival professions. As noted by Julia Hendry, the growing emphasis on inquiry-based learning in combination with document-based questions on standardized tests has inspired K-12 educators to incorporate primary sources into the curriculum. ${ }^{1}$

Archivists have observed these developments and have been motived by existing museum education programs, opportunities for digitization and online access to primary sources, the prospect of improving the quality of teaching, and increasing societal awareness and support of archives. ${ }^{2}$ Both professions have produced a substantial body of literature on teaching with primary sources in $\mathrm{K}-12$ and higher education. Studies on archivists' efforts in the college and university classroom reveal common approaches, focusing on teaching critical thinking skills through lectures and document analysis exercise. ${ }^{3}$

In recent years at the Special Collections Research Center (SCRC) at Southern Illinois University-Carbondale, archivists have partnered with Department of Radio, Television, and Digital Media faculty to teach with primary sources in an alternative way. A unit of the course Sound Art and Practice II, titled Sound Conservation, recognizes this archival task as an aspect of the ap- plications of sound as art and function. During the unit, under the supervision of the university archivist, students received practical experience by digitizing oral history cassettes and creating descriptive and technical metadata. Instead of teaching critical thinking and research methods using primary sources, the materials were used to broaden the experience and skill sets of students in ways relevant to their major but traditionally foreign.

The unit raised awareness of the existence of historic sound collections, and exposed them to an alternative career outside of the traditional studio setting. The collaboration is also unique in that students from a discipline other than library science or history learned relevant professional skills through archival work.

The Betty Mitchell Collection was selected for the spring 2014 iteration of this partnership. The collection consists primarily of oral histories recorded on 76 cassette tapes, along with rough transcripts, documenting the tenure of former university president Delyte W. Morris. No systematic selection process determined which interviews to digitize. The tapes are arranged alphabetically by interviewee and were digitized in that order. The length of the interviews ranged from 30-to-90

Matt Gorzalski, is university archivist at Southern Illinois University-Carbondale, email: mgorzalski@lib.siu.edu () 2015 Matt Gorzalski 
minutes. Each of the 13 students digitized one oral history.

This month-long collaboration began when I lectured on the aspects of recorded sound preservation in both physical and digital formats. I discussed the value of preserving sound recordings, the typical recording formats found in most archives, and highlighted specific audio collections in SCRC. This was followed with an overview of proper handling and storage of physical recordings, and the consequences of not following these best practices. Finally I discussed digitization as a preservation method, focusing on best practices for file formats, capture specifications such as sample rate and bit depth, and the types of metadata with emphasis on descriptive and technical.

Each student signed up for a two-hour time slot over a four-week period to complete the hands-on assignment for the Sound Conservation unit. To begin the session, students received a short explanation of how to use the digitization equipment, as well as a review of the metadata fields they would enter into the audio metadata database. The necessity of creating quality metadata in the strict two-hour time limit required close supervision of each student's lab session.

The students drafted their metadata on digital worksheets before entering the revised description into the database. The metadata fields, based on Dublin Core, included: Collection ID, Title, Creator(s), Geographical, Description, Medium, Date (original), Run Time, Subjects (LCSH), Collection/Box Number, Type, Rights Statement, Publisher, File Name, Date Digitized, Notes, and Collection.

The students used cassette labels, the Betty Mitchell Collection finding aid, and the rough transcripts to create as much initial metadata as possible, which satisfied all fields except Description, Subject, Run Time, and File Name. As the cassette played, the students wrote subject ideas on scratch paper, which were later matched to corresponding Library of Congress Subject Headings under the guidance of the university archivist. The Description field summarized interview highlights and incorporated subject terms.

The digitization process and creating the preservation and access files went smoothly. I was surprised that only one student admitted to having previously digitized an analog recording. Additionally, no student had experience with Sony Sound Forge, a popular audio capture and processing software used by some preservation laboratories. It was also interesting, though unsurprising, that no students had a formal understanding of metadata.

During the lecture I gave examples of simple metadata, such as title and author, that the students easily understood. However, they struggled with identifying subject terms and creating descriptive scope notes. The terms students devised were often too granular to match the broad LCSH headings, and they needed guidance on identifying general themes and topics of the interviews. Despite explanation on identifying subject terms, most students focused solely on the central topic, Delyte W. Morris, and did not consider the bigger picture, such as the interviewees themselves as subjects and their roles at the university. In all cases, I had to dictate the descriptive notes, as certain expected information was often overlooked.

I learned several valuable lessons during this project that will influence future digitization projects. Because of the length of the oral histories, ranging from 30-to-90 minutes, students were pressed for time to complete the assignment in the two-hour time slots.

In previous years, when I was not involved in this collaboration, students digitized 15-minute recordings from WSIU Public Broadcasting Station. But this collection was completely digitized by the time of my involvement. Additionally, most alternative length-appropriate audio collections were also digitized. Given its 


\section{Interested or not, the students learned how metadata contributes to the understanding of physical and digital objects, and how it is crucial for sup- porting long-term digital preservation.}

significant topic, the Betty Mitchell Collection warranted digitization, but unlike the WSIU recordings, the Mitchell cassettes were not labeled with recording lengths, and the author was left to guesstimate. The longer recording times put constraints on metadata creation. Most students finished in two hours but used the entire time, while a few went longer because of the recording length. In the future, perhaps 2.5 hour time slots would be more appropriate.

The students also ran into difficulties using the MS Access audio metadata database, particularly with the description note and subject headings. The Access database text fields have a 255 character limit, and as a result, the description and subject terms for some oral histories did not adequately capture all the topics of the recordings. In these cases the student had to write the description in strategic fragments rather than complete sentences, and sometimes had to exclude relevant but less important subject terms. Access allows longer text fields, but I ran into difficulties making the conversion. Ultimately the problem was solved, but archivists may wish to explore options other than MS Access for lengthy metadata.

Finally, it is clear that good metadata takes practice. While the students were capable of digitizing on their own, I had to closely monitor the metadata creation, which was a significant time commitment. Most students were indifferent or only moderately interested in this aspect of archival work. However, one student expressed genuine enthusiasm for historic sound collections and the physical formats shown during the lecture.

Interested or not, the students learned how metadata contributes to the under- standing of physical and digital objects, and how it is crucial for supporting long-term digital preservation.

Despite some difficulties, the collaborative project has been mutually beneficial. Special Collections assisted in supporting the course objectives of exploring sound as an art form and learning hands-on approaches with audio technologies. In return, the students digitized and described several oral histories; a project that would have been difficult with Special Collection's limited staffing resources.

This project is exemplary of how special collections can collaborate with faculty from different departments and use archival materials to aid teaching in ways other than traditional document analysis exercises.

\section{Notes}

1. Julia Hendry, "Primary Sources in K-12 Education: Opportunities for Archives," The American Archivist 70 (2007): 116.

2. Ken Osborne, "Archives in the Classroom," Archivaria 23 (Winter 1986-87): 16-17; Anne J. Gilliland-Swetland, "An Exploration of K-12 User Needs for Digital Primary Source Materials," The American Archivist 61 (Spring 1998): 136-157.

3. Some examples include: Marcus C. Robyns, "The Archivist as Educator: Integrating Critical Thinking Skills into Historical Research Methods Instruction," The American Archivist 64 (2001): 363384; James Grerencser and Malinda Triller, "Hands-on Instruction in the Archives: Using Group Activities as an Engaging Way to Teach Undergraduates about Primary Sources," Journal for the Society of North Carolina Archivists 6:2 (2009): 55-66; Barbara Rockenbach, "Archives, Undergraduates, and Inquiry Based Learning: Case Studies from Yale University Library," American Archivist 74 (spring/summer 2011): 297-311; Peter Carini, "Archivists as Educators: Integrating Primary Sources into the Curriculum," Journal of Archival Organization 7:1-2 (2009): 41-50. $\boldsymbol{n}$ 